\title{
MECHANICAL STRENGTH OF DISSIMILAR AA7075 AND AA6061 ALUMINUM ALLOYS USING FRICTION STIR WELDING
}

\author{
N.A.A. Sathari ${ }^{1 *}$, A.R. Razali ${ }^{1}$, M. Ishak ${ }^{1}$ and L.H. Shah ${ }^{1}$ \\ ${ }^{1}$ Faculty of Mechanical Engineering, Universiti Malaysia Pahang, \\ 26600 Pekan, Pahang, Malaysia \\ *Email: ainamelia@ hotmail.co.uk \\ Phone: +60135904388; Fax: +6094246222
}

\begin{abstract}
The present study focuses on the effects of material position and tool rotational speed on the tensile strength of dissimilar AA7071 and AA6061 welded aluminum alloys with a thickness of $2.0 \mathrm{~mm}$ in using a conventional milling machine. Ten joints were produced by varying tool rotational speeds and by changing the fixed position of the material on the advancing and retreating sides. The results show that the maximum tensile strength of $207 \mathrm{MPa}$ was achieved for Sample E when AA6061 aluminum alloys were placed on the advancing side at a rotational speed of $1000 \mathrm{rpm}$ with seamless surface appearance and no inner defect across the weld area, while the lowest tensile strength of $160 \mathrm{MPa}$ was obtained for Sample F when AA6061 was placed on the retreating side with severe tunnel defects across the weld area contributing to crack propagation. Thus, in dissimilar welding, weaker materials should be placed on the advancing side to trigger heat from the tool rotation and smooth the material flow formation in the stirred zone.
\end{abstract}

Keywords: Friction stir welding; rotational speeds; aluminum alloys; tensile strength.

\section{INTRODUCTION}

Friction stir welding (FSW), invented and patented at The Welding Institute ((TWI), is a novel solid-state welding technology that has been widely used for joining alloys and metals [1-3]. The FSW process operates below the solidus temperature of the metals being joined and the use of filler material is not required. During the FSW process, a non-consumable rotating tool with a pin and shoulder that provide 'stir' action is inserted into the abutting edges of the plates to be joined and will move along the join line. The rotating tool moves along the weld line and creates frictional heating of the material, causing it to plasticize where it cools and consolidates to produce a high integrity weld [3-7]. Nowadays, the automotive industry demands vehicles with greater performance, energy savings and environmental preservation at lower cost [6]. Since reducing the weight is an efficient measure, the combination of dissimilar grades of aluminum alloy has increased in fabricating vehicles [1]. This effort is being carried out by the substitution of light materials, especially aluminum. However, so far it has been difficult to produce a sound joint by conventional fusion welding methods alone and FSW technology has been chosen as it appears to be a promising technique that produces high weld efficiency and is capable of joining materials that are usually difficult to weld using conventional welding methods. Due to the high demand for joined dissimilar materials for new structures or parts with mixed material properties, especially in the automotive industry, AA6061 and AA7075 aluminum alloys were 
selected for the FSW process in this study. AA6061 alloys are high strength, have high corrosion resistance and are lightweight aluminum with high ductility and toughness [4]. Meanwhile, AA7075 exhibits super high strength that has been used extensively in aircraft components and other highly stressed applications. Both materials of the AA6061 and AA7075 series are extensively employed in marine fittings, automobiles and aircraft applications [8].

Successful studies on dissimilar materials by Khodir and Shibayanagi [9] show the improvement in the joint made in the FSW of dissimilar AA2024 and AA7075 aluminum alloys by varying the welding speed and fixed location of the base metals. It was found that the mechanical properties of the welded joint are improved at a welding speed of $1.67 \mathrm{~mm} / \mathrm{s}$ and when placing AA2024 on the advancing side [10]. Ravikumar and Rao [11] studied the macro and micro structural characteristics of the dissimilar FSW of an AA7075-T651 and AA6061-T651 butt joint which presents better mixing of both materials and good weld strength at $900 \mathrm{rpm}, 90 \mathrm{~mm} / \mathrm{min}$ with a tapered cylindrically threaded tool [12]. Ghosh, Kumar [13] researched the optimization of the A356 and AA6061 FSW parameters by varying the tool rotational speeds of 1000-1400 $\mathrm{rpm}$ and traversing speeds of $80-240 \mathrm{~mm} / \mathrm{min}$ that are responsible for the change in total heat input and cooling rate during the FSW process. Joint improvement in the weld strength was produced at the lowest tool traversing and rotational speeds, more than $98 \%$ of the 6061 alloy [13].

In addition, Amancio-Filho, Sheikhi [1] found defect-free friction stir welds in dissimilar AA2024-T351 and AA6056-T4 alloy systems in a preliminary study on the microstructure and mechanical properties of aircraft alloys. Furthermore, tensile tests have shown reasonable joint efficiencies in terms of ultimate tensile strength which produces around $56 \%$ of the 2024-T351 and about $90 \%$ of the 6056-T4 alloy strengths[14]. Li and Shen [15] proved that improved weld strength of dissimilar welded AA6063 and AA5052 is achieved by using a further designed quench hardening tool of the W9Mo3Cr4V type with some geometric improvements. Other than that, the studies show that the material position at the retreating side benefited the formation of the weld and the interfacial gap between the lap materials is reduced in the feasibility research on the FSW process of the new-type lap-butt joint of dissimilar Al alloys [15]. Thus, to incorporate these dissimilar aluminum material joints, the FSW feasibility parameters are important in order to produce better bond strength. It is proved that previous research showed good findings in the dissimilar FSW of aluminum alloys, and has shown enormous potential to be implemented in various industries. Unfortunately, the study of AA7075 and AA6061 has been limited, despite the vast industrial applications for both materials. In this study, an attempt is made to join $2.0 \mathrm{~mm}$ thick plates of AA7075 and AA6061 using FSW and to investigate the effects of rotational speed and base material positioning on the tensile properties.

\section{MATERIALS AND METHODS}

\section{Materials}

Aluminum alloy AA7075 and AA6061 plates of $100 \mathrm{~mm} \times 50 \mathrm{~mm} \times 2 \mathrm{~mm}$ were used in this study and clamped rigidly to the backing plate for welding. Tables 1 and 2 show the chemical composition and physical properties of AA7075 and AA6061 that stated the percentage of chemical composition and physical criteria in both alloys that contras them in strength, ductility and microstructure. 
Table 1. Chemical compositions of AA6061 and AA7075 alloys (wt \%).

\begin{tabular}{llllllllll}
\hline Alloy & $\mathrm{Zn}$ & $\mathrm{Mg}$ & $\mathrm{Cu}$ & $\mathrm{Mn}$ & $\mathrm{Si}$ & $\mathrm{Fe}$ & $\mathrm{Ti}$ & $\mathrm{Cr}$ & $\mathrm{Al}$ \\
& & & & & & & & & \\
\hline AA6061 & 0.25 & $0.8-$ & $0.15-0.4$ & 0.15 & $0.4-$ & 0.7 & 0.15 & $0.04-$ & Bal. \\
& & 1.2 & & & 0.8 & & & 0.35 & \\
\hline AA7075 & $5.1-6.1$ & $2.1-2.9$ & $1.2-2.0$ & 0.3 & 0.4 & 0.5 & 0.2 & $0.18-0.28$ & Bal. \\
\hline
\end{tabular}

Table 2. Physical properties of AA6061 and AA7075 alloys.

\begin{tabular}{ccccc}
\hline Properties & $\begin{array}{c}\text { Melting } \\
\text { point }\end{array}$ & $\begin{array}{c}\text { Solidus } \\
\text { temperature }\end{array}$ & $\begin{array}{c}\text { Thermal conductivity } \\
(\mathrm{W} / \mathrm{m}-\mathrm{K})\end{array}$ & $\begin{array}{c}\text { Tensile strength } \\
(\mathrm{MPa}) / \text { Hardness }\end{array}$ \\
\hline AA6061 & $652{ }^{\circ} \mathrm{C}$ & $582{ }^{\circ} \mathrm{C}$ & 167 & $353 / 96 \mathrm{Hv}$ \\
$\mathrm{AA7075}$ & $635^{\circ} \mathrm{C}$ & $477 \circ^{\circ} \mathrm{C}$ & 130 & $572 / 175 \mathrm{Hv}$ \\
\hline
\end{tabular}

\section{Experimental Procedure}

The tool used was a cylindrical plain type of H13 steel. Figure 1 shows the tool design used in this FSW process and Table 3 shows the tool dimensions. The as received $20 \mathrm{~mm}$ diameter rod of $\mathrm{H} 13$ tool material was processed on a lathe in accordance with the specified dimensions.

Table 3. Tool dimensions.

\begin{tabular}{lc}
\hline \multicolumn{1}{c}{ Pin } & Values $(\mathrm{mm})$ \\
\hline Pin length, & 1.7 \\
Tool shoulder diameter, D & 18 \\
Pin diameter, d & 6 \\
Holder diameter & 8 \\
Holder length & 36 \\
Shoulder length & 10 \\
\hline
\end{tabular}

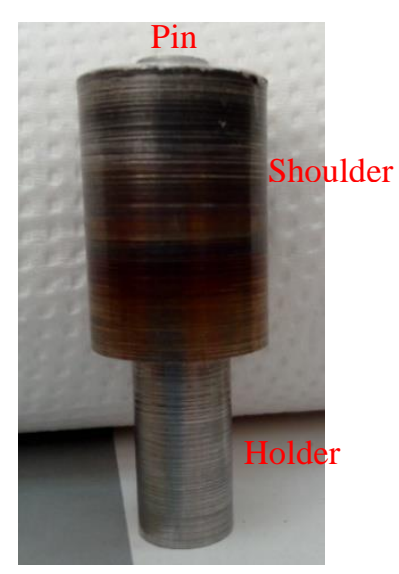

Figure 1. FSW tool. 
The FSW process was carried out on the VMM3917 Partner vertical milling machine with butt joint configuration. The welding speed and tool tilt angle were kept constant at $100 \mathrm{~mm} / \mathrm{min}$ and $3^{\circ}$, respectively. The variable parameters are rotational speed (rpm) and the material position. The process was undertaken using two separated groups, Group A and Group B, with five consecutive values of rotational speed,800 rpm, $900 \mathrm{rpm}, 1000 \mathrm{rpm} 1200 \mathrm{rpm}$ and $1400 \mathrm{rpm}$, and changes to the fixed position of the materials for each group as shown in Table 4.

Table 4. Welding plan of dissimilar joints.

\begin{tabular}{cccc}
\hline $\begin{array}{c}\text { Group } \\
\text { (A/B) }\end{array}$ & $\begin{array}{c}\text { Tool rotational speed } \\
(\mathrm{rpm})\end{array}$ & $\begin{array}{c}\text { Material at advancing side } \\
(\mathrm{AS})\end{array}$ & Sample label \\
\hline A & 800 & AA6061 & A \\
A & 800 & AA7075 & C \\
A & 900 & AA6061 & E \\
A & 900 & AA7075 & G \\
A & 1000 & AA6061 & I \\
B & 1000 & AA7075 & B \\
B & 1200 & AA6061 & D \\
B & 1200 & AA7075 & F \\
B & 1400 & AA6061 & H \\
B & 1400 & AA7075 & J \\
\hline
\end{tabular}

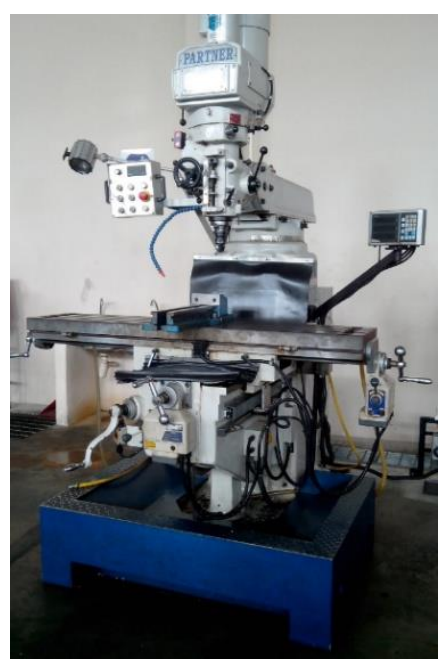

Figure 2. Milling machine (VMM3917 Partner).

All ten joints were welded using the selected parameter range with different fixed positions of the material to evaluate its tensile characteristics. Tensile samples were cut using an electrical discharge machining (EDM) wire cutting machine and were ground smooth to remove any defects that might affect the tensile result. Tensile strength of the welded specimens was investigated using a tensile test machine, an INSTRON Bluehill machine. The dimensions for the tensile specimens are in accordance with standard ASTM E8. Three tensile specimens were prepared for each weldment and the average ultimate tensile strength [16] value was taken. 


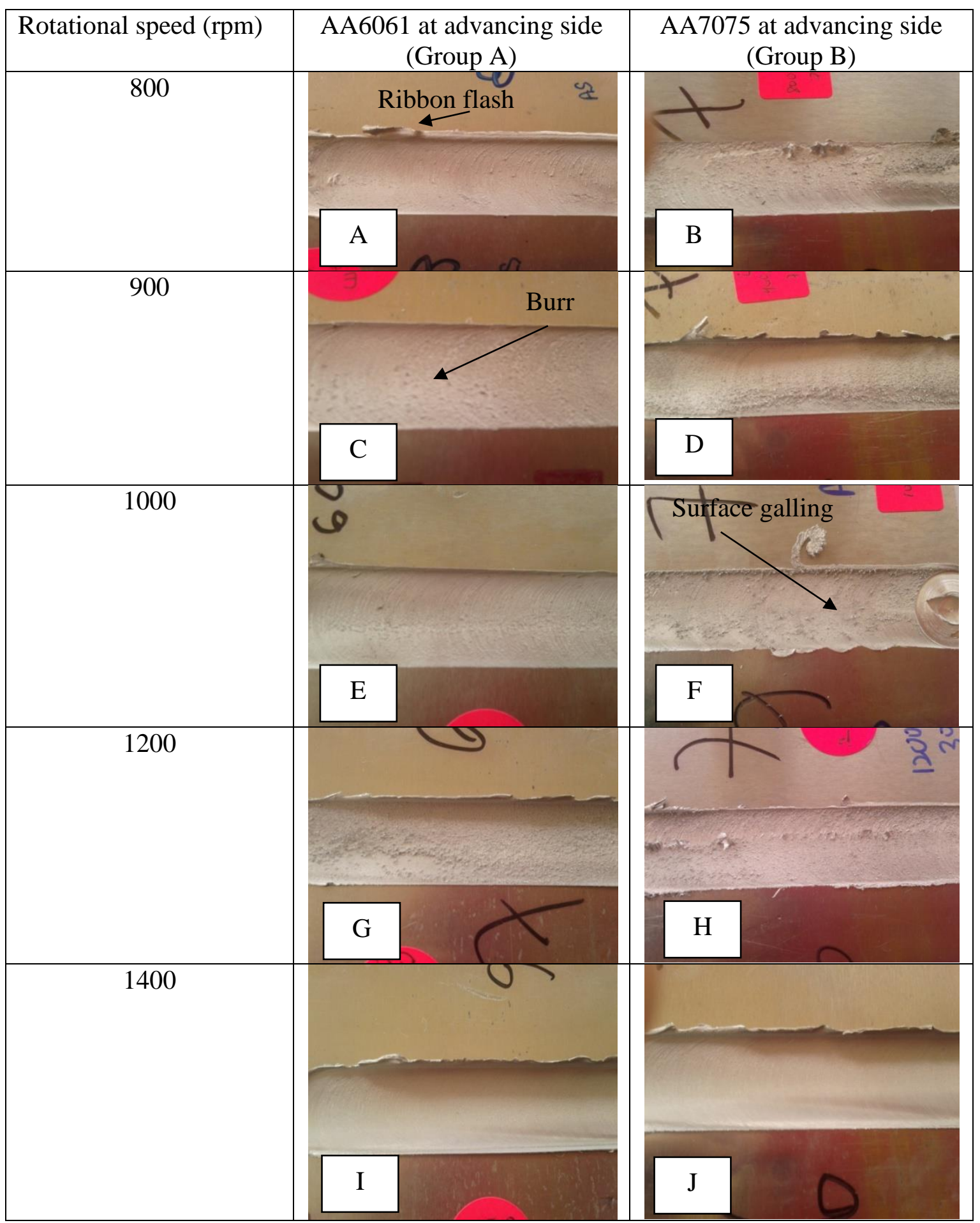

Figure 3. Weld appearance (top view) for welded specimens

\section{RESULTS AND DISCUSSION}

Figure 3 shows the FSW welded samples with different rotational speeds of $800 \mathrm{rpm}$, $900 \mathrm{rpm}, 1000 \mathrm{rpm}, 1200 \mathrm{rpm}$, and $1400 \mathrm{rpm}$, respectively. The best weld appearance, clear from severe FSW defects and with a smooth surface, was produced at $1000 \mathrm{rpm}$ when AA6061 was positioned on the advancing side. Ribbon flash defects were found on some welded specimens from Samples A, D, G, I and J. Ribbon flash is an excessive 
expulsion of material on the top surface leaving a ribbon like effect which occurs due to excessive forge load or an excessively hot weld. Other defects that occur in the FSW process are burr and surface galling that can be seen in most of the samples. These defects resulted from the metal sticking to the pin tool and from excessively hot welds. Some severe defects occurring in the FSW specimens can cause degradation of its mechanical properties [17]. The weld appearance is affected by the heat input being supplied by the tool rotational speed during FSW jointing. In Figure 3(F), the defect shown is surface galling which is due to the material sticking to the tool pin and the low travelling speed. These defects can reduce the strength of the welded joints and can be prevented by increasing the axial force pressure and increasing the rotational speed so that the stirring action between materials will smooth the formation of the flow arm at the weld line [15].

Tensile tests were undertaken for the joining of dissimilar aluminum. Figure 4 presents the tensile strength results of the dissimilar aluminum weldments. From the graph, it can be observed that Sample E has the maximum UTS of $207 \mathrm{MPa}$ at $1000 \mathrm{rpm}$ when the AA6061 was positioned on the advancing side and Sample F exhibited lowest UTS at $160 \mathrm{MPa}$ when the AA7075 was positioned on the advancing side at $1000 \mathrm{rpm}$. From the overall results of Group A (AA6061 on the advancing side), it can be observed that when the rotational speed increases from $800 \mathrm{rpm}$ to $1000 \mathrm{rpm}$, the tensile strength also increases. However, the strength started to decrease slightly at $1200 \mathrm{rpm}$ and above. Meanwhile for Group B (AA7075 on the advancing side), the results show an increase in tensile strength proportional to the rotational speed, as with Group A, but this abruptly decreased at $1000 \mathrm{rpm}$, followed by an improvement in tensile strength at a rotational speed of $1200 \mathrm{rpm}$ and $1400 \mathrm{rpm}$.

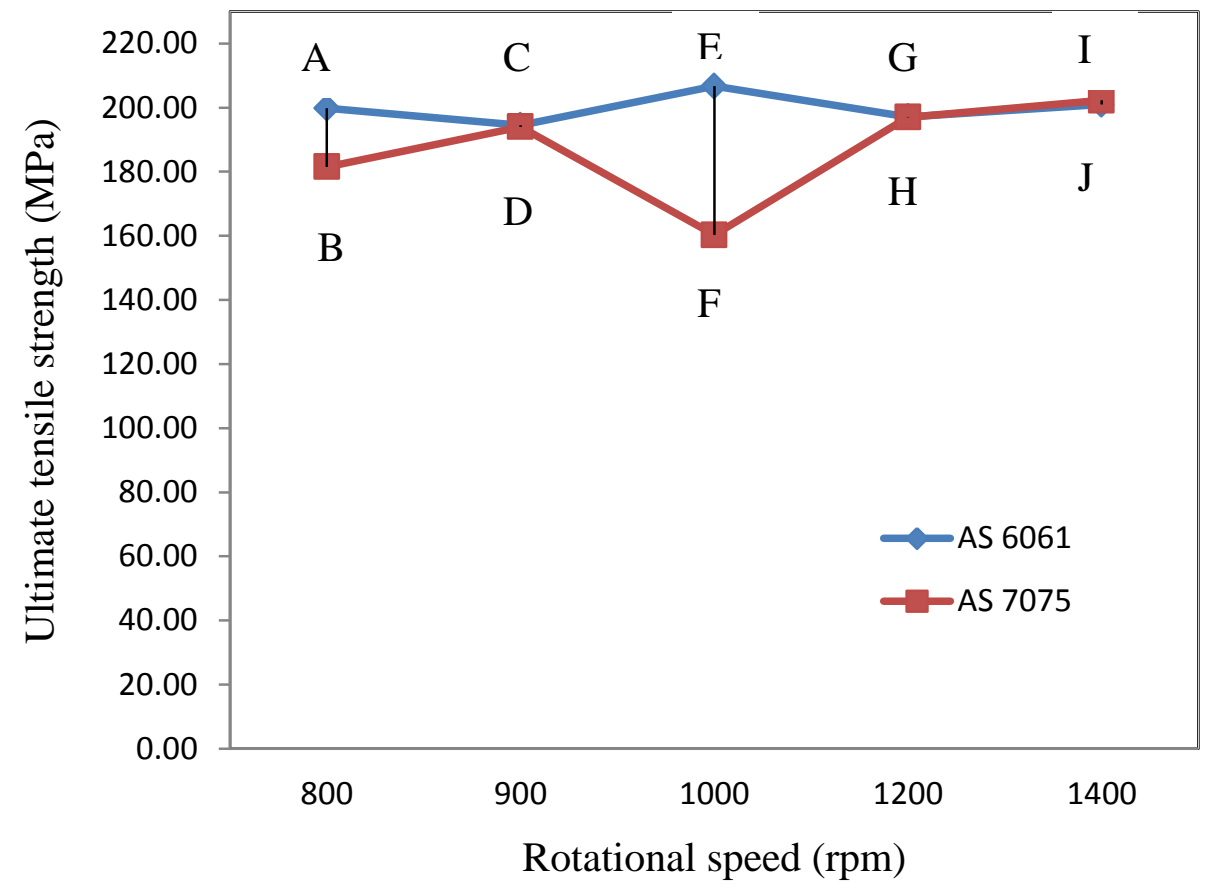

Figure 4. Tensile strength of dissimilar AA6061 and AA7075 aluminum alloy joints.

Figure 5 shows an example of fractured specimens from the tensile tests for Sample F (Figure 5a). As proved by previous researchers, the FSW joints basically 
fractured on the side of the lower strength material that has a minimum hardness value $[12,18]$. Therefore, the fracture in the heat affected zone (HAZ) also proved that a seamless joint is achieved in this experiment. Meanwhile, Figures 5(b) and 5(c) show the cross section area from Samples E and F respectively. All joints fracture in the HAZ zone on the AA6061 part, as proven previously for Group A in which the material on the advancing side is AA6061. The tensile strength value increases to a maximum at $1000 \mathrm{rpm}$ and starts to decrease beyond $1200 \mathrm{rpm}$. The maximum UTS was achieved in Sample E because the higher tool rotation rates produce a higher friction rate and generates higher temperature. Thus, this results in intense mixing of the material and the heat supplied is sufficient to soften and stir the plasticized materials and smooth consolidation is achieved equally on the retreating side [5]. Even so, for Group A this shows the decrement of tensile strength with further increases in tool rotational speed. This is due to low heat input as the rotational speed increase up to $1400 \mathrm{rpm}$ and mixing actions in the materials become a little excessive when the tool rotational speed is too high and affects the transportation rate from the advancing side to the retreating side. Almost all samples for both groups are defect-free welds and produce sound joints except for Sample F that has the lowest UTS which is due to surface galling (Figure 3F) and tunnel defects (Figure 6b) inside the weldment which contribute to fracture and crack propagation in the defect area.

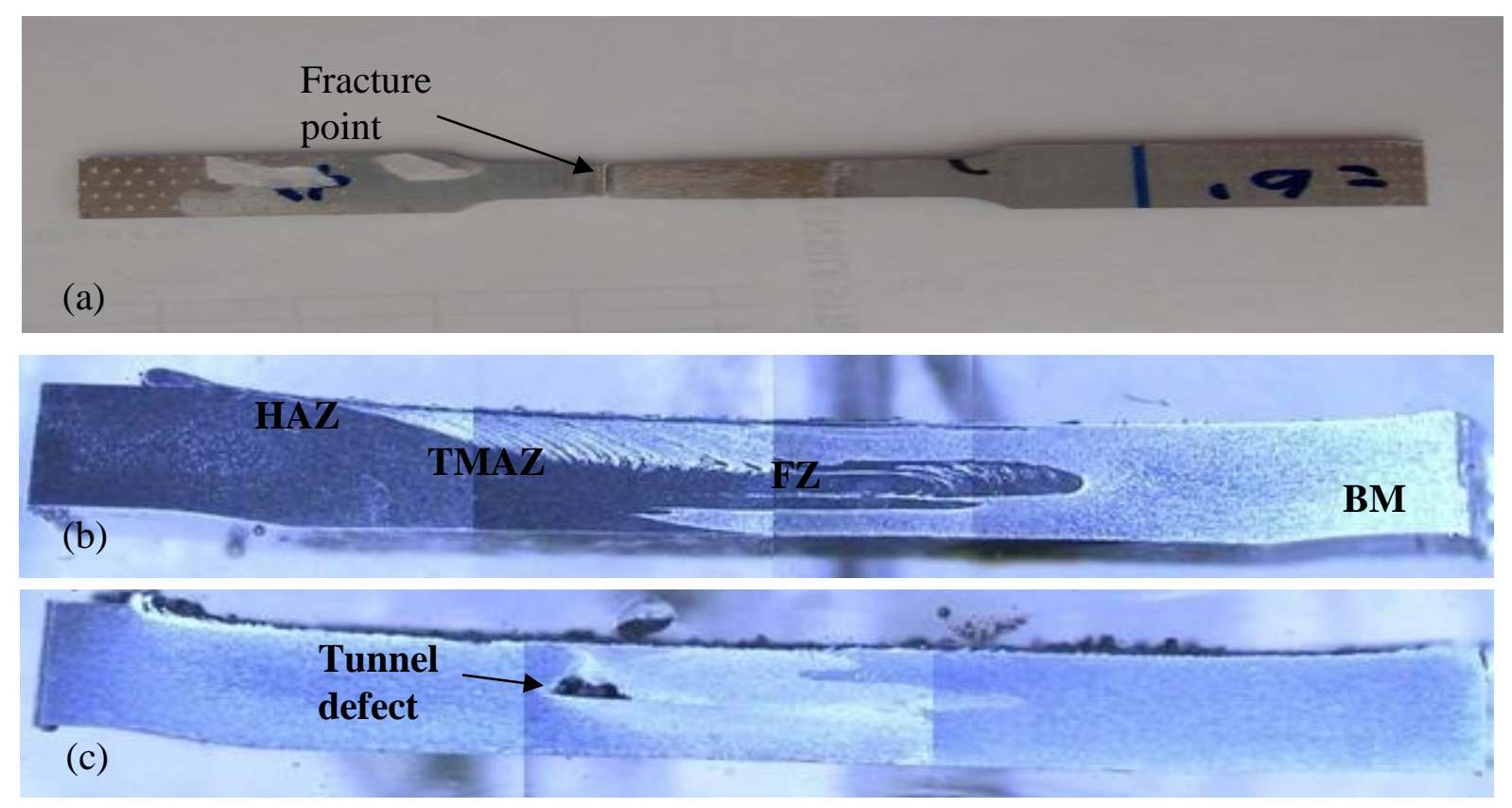

Figure 5(a). Fractured Sample F;(b). Weld cross section area of Sample E;(c). Weld cross section area of Sample F.

\section{CONCLUSIONS}

The FSW process of dissimilar AA6061 and AA7075 aluminum alloys was successfully conducted and the results obtained can be summarized as follows:

i) The surface weld appearance depends on the heat input that corresponds to the rotational speed and material location during the FSW process. The rotational speed of $1000 \mathrm{rpm}$ with AA6061 positioned on the advancing side 
for Group A resulted in a better surface weld appearance with sound joints and no severe defects.

ii) Sample E exhibits the maximum tensile strength value of $207 \mathrm{MPa}$ with a rotational speed of $1000 \mathrm{rpm}$ and with AA6061 positioned on the advancing side, compared to Sample H with AA7075 positioned on the advancing side with a minimum tensile strength of $160 \mathrm{MPa}$ due to severe tunnel defects inside the weldment and surface galling that contribute to failure.

iii) This study shows that a weaker material dictates the performance of the weldment where failure occurs in the strength reduction region of the AA6061 at the HAZ. In future studies, it is suggested that stronger materials should be placed at the retreating side instead of the advancing side.

\section{ACKNOWLEDGEMENTS}

The author would like to thank the supervisors and technical staffs in Universiti Malaysia Pahang, all of the work within which experiment were conducted. The financial support by Ministry of Education Malaysia through Universiti Malaysia Pahang for Fundamental Research Grant Scheme (FRGS), project no. FRGS/1/2013/TKOI/UMP/02/2 is also grateful acknowledged.

\section{REFERENCES}

[1] Amancio-Filho ST, Sheikhi S, dos Santos JF, Bolfarini C. Preliminary study on the microstructure and mechanical properties of dissimilar friction stir welds in aircraft aluminium alloys 2024-T351 and 6056-T4. Journal of Materials Processing Technology. 2008;206:132-42.

[2] Sathari NAA, Shah LH, Razali AR. Investigation of Single-Pass/Double-Pass Techniques on Friction Stir Welding of Aluminium. Journal of Mechanical Engineering and Sciences. 2014;7:1053-61.

[3] Shah LH, Akhtar Z, Ishak M. Investigation of aluminum-stainless steel dissimilar weld quality using different filler metals. International Journal of Automotive and Mechanical Engineering. 2013;8:1121-31.

[4] Mukhopadhyay P. Alloy designation, processing, and use of AA6XXX series aluminium alloys. ISRN Metallurgy. 2012;2012:1-15.

[5] Dinaharan I, Kalaiselvan K, Vijay SJ, Raja P. Effect of material location and tool rotational speed on microstructure and tensile strength of dissimilar friction stir welded aluminum alloys. Archives of Civil and Mechanical Engineering. 2012;12:446-54.

[6] Pumchan W. The influences of the friction stir welding on the microstructure and hardness of aluminum 6063 and 7075. International Conference on Advanced Materials Engineering 2011:31-5.

[7] Charde N. Microstructure and fatigue properties of dissimilar spot welds joints of AISI 304 and AISI 1008. International Journal of Automotive and Mechanical Engineering. 2013;7:882-99.

[8] Rajakumar S, Muralidharan C, Balasubramanian V. Optimization of the frictionstir-welding process and tool parameters to attain a maximum tensile strength of AA7075-T6 aluminium alloy. Proceedings of the Institution of Mechanical Engineers, Part B: Journal of Engineering Manufacture. 2010;224:1175-91. 
[9] Khodir SA, Shibayanagi T. Friction stir welding of dissimilar AA2024 and AA7075 aluminum alloys. Materials Science and Engineering: B. 2008;148:827.

[10] Khodir K, Ahmed S, Shibayanagi T. Friction stir welding of dissimilar AA2024 and AA7075 aluminum alloys. Materials Science and Engineering: B. 2014;148:82-7.

[11] Ravikumar S, Rao V. Microstructural Characterizations with EDAX Analysis of Dissimilar Friction Stir Welds. Journal of The Institution of Engineers (India): Series C. 2013;94:307-15.

[12] Koilraj M, Sundareswaran V, Vijayan S, Rao S. Friction stir welding of dissimilar aluminum alloys AA2219 to AA5083 - Optimization of Process Parameters Using Taguchi Technique. Materials \& Design. 2014;42:1-7.

[13] Ghosh M, Kumar K, Kailas SV, Ray AK. Optimization of friction stir welding parameters for dissimilar aluminum alloys. Materials \& Design. 2010;31:30337.

[14] Wang J, Lu MX, Zhang L, Chang W, Xu LN, Hu LH. Effect of welding process on the microstructure and properties of dissimilar weld joints between low alloy and duplex stainless steel. International Journal of Minerals, Metallurgy and Materials. 2012;19:518-24.

[15] Li B, Shen Y. A feasibility research on friction stir welding of a new-typed lapbutt joint of dissimilar al alloys. Materials \& Design. 2014;34:725-31.

[16] Marchebois H, Piette M, Ladeuille L, Rouviere DS, Bosch C, Pleschiutschnig J, et al. Development Of A C125 High Strength Low Alloy Steel For Octg: Ssc Mapping In Slightly Sour Environment. Corrosion, NACE International; 2008.

[17] Arbegast WJ. A flow-partitioned deformation zone model for defect formation during friction stir welding. Scr Mater. 2008;58:372-6.

[18] da Silva AAM, Arruti E, Janeiro G, Aldanondo E, Alvarez P, Echeverria A. Material flow and mechanical behaviour of dissimilar AA2024-T3 and AA7075T6 aluminium alloys friction stir welds. Materials \& Design. 2011;32:2021-7. 